\title{
Kitap İncelemeleri
}

\section{Book Reviews}

Sinemada Zaman: Ritmik Tasarım; Türbülans ve Akış - Yvette Biro

Inceleyen: Ulaş Işıklar

\author{
Sinemada Zaman: Ritmik Tasarım; Türbülans ve Akış \\ Yazar: Yvette Biro \\ Kitabın Özgün Adı: Turbulence and Flow in Film: The Rhythmic Design \\ Çeviren: Anıl Ceren Altunkanat \\ Doruk Yayımcılık, Cağaloğlu, 2011, 274 s. \\ ISBN: 978-975-553-540-1
}

New York Üniversitesi Sinema Bölümü'nden profesör unvanıla emekli olan Yvette Biro, aynı zamanda senaryo yazarlığı ve denemecilik de yapan çok yönlü bir entelektüeldir. Ülkesi Macaristan'da çok sayıda ünlü yönetmenle ödüllü pek çok filmde birlikte çalışmıştır. Sinema konusunda birçok kitabı, denemesi ve çevirisi bulunmaktadır. Sinema üzerine başlıca eserleri arasinda Sinemada Zaman, The Metamorphosis of the Image, The Seventh Art ve Profane Mythology sayılabilir.

İncelenen bu çalışma, Biro'nun kendi ifadesiyle, "Yavaşlığa Övgü" alt başlığını taşıyan ve 1990'lı yılların ortasında yazılan "Yavaş Yavaş Acele Et" adlı denemenin genişletilmesiyle ortaya çıkmıştır. Söz konusu denemenin "fazlasıyla ayrıcalık kazanmış hızlı tempo kullanma modasının" geçerli olduğu bir dönemde yazıldığını belirten Biro, başlangıçta "daha sabırlı ve sakin bir öykü anlatıcılığının gücünü tartışmak" niyetinde olduğuna fakat analizleri derinleştikçe, filmin ritim ve temposunu belirleyen hız ve yavaşlık arasındaki ilişkinin tam bir karşıtlıktan ziyade birbirine bağımlılıkta kendini gösterdiğine dikkat çekmektedir. Buna göre, bahsi geçen ilişkinin filmsel zaman temelinde ortaya çıardığ 1 işlevler zıtlık değil, tam tersine, girift bir detaylandırma bağlamında anlaşılabilmektedir.

Sözü edilen "girift" anlayışa uygun şekilde çalışma, T. S. Eliot'un "Geçmiş zaman ve gelecek zaman, Olmuş olabilecek ve olmuş olan, İşaret eder her zaman şimdi/burada bulunan sona" dizeleriyle başlamaktadır. Bu dizelerin, metnin ruhunu yansıtması bakımından isabetli bir giriş seçimi olduğunu söylemek mümkündür. Biro'nun filmsel zamanı tayin eden temel kavramlar olarak imlediği "türbülans" ve "akış" terimleri, söz konusu "birbirine geçmeye" gönderme yapmaktadır. Buna göre, bir film basit şekilde hızlı veya yavaş tempolu olarak değerlendirilemez. Filmin ritmik tasarımı, bundan çok daha fazla ve ayrıntılı katmanları içermektedir. Dolayısıyla, bir filmin zamansal boyutunu da doğrudan belirleyen anlatı yapısındaki ritim ve temponun oluşumunu, salt neden-sonuç ilişkileri bağlamında düşünmek fazla basitleştirici bir yaklaşımdır. Bunun yerine, "konudan sapmalar, kesmeler ve 
yinelemeler, düşler, anılar ve fanteziler" gibi anlatısal unsurların da denkleme dâhil edilmesi gerekmektedir. Çünkü bu söz konusu unsurlar, "sürekli bir bütünün yaratımında kaçınılmaz" olmalarının yanı sıra, filmsel ritim ve tempoya doğrudan etkide bulunarak anlatının zamansal niteliğini de biçimlendirmektedir. Bundan dolayı, Biro'ya göre, "hayret, sürpriz, bilinmeyen ve hatta olaysız durumlar, en az hızlı ardışıklıklar kadar anlatının içeriği" anlamına gelmektedir.

$\mathrm{Bu}$ çerçevede metin, filmin devamlılı̆̆ının, yani ritim ve temposunu oluşturan ve böylece zamansal yapısını da şekillendiren öğelerinin birleşiminin, montaja dayalı salt teknik bir araya getirme süreci olmadığına işaret etmektedir. Bunun daha ötesinde, "düz akmayan bir nehir" olarak metaforlaştırılan anlatı, "kıvrımlar ve dönüşler, çatallanmalar, yinelemeler ve öngörülemez engeller" bağlamında ortaya çıkmaktadır. İlkesel zorunluluk gereği "türbülans ve akışın akımına dayanan" öykü anlatıcılığı, anlatının doluluk ve doygunluğunu da belirleyen kesmeler, vuruşlar ve duraklamaların oluşturduğu parçaların birleşimiyle şekillenen bütünleştirme işlemidir. Dolayısıyla, söz konusu parçalar, kendilerinden fazlasını temsil etmektedir.

Metnin düşünsel çerçevesini bu şekildeki bir bağlama oturtan Biro, yapısal olarak ise on başlık tercih etmiştir. "Uçarı Zaman”, “Tempoyu Ayarlamak”, "Karışık (Genişletilmiş) Öykü Yapıları”, “Konudan Sapmak”, “Zamanda Görmek: Quasi una pausa”, “Yinelemeler ya da Yenileme", "Odiseuslar", "Günlük Ritüeller", "Sonlanışlar" ve "Zamanın Stratejileri" biçiminde sıralanan ana bölümler, kendi içinde de fragmanlara ayrılmaktadır. Her bir başlık içindeki alt başlıklar çerçevesinde, yakın ya da uzak tarihli sinema filmlerinden örneklerle düşünceler açımlanmaktadır.

“Uçarı Zaman" adlı ilk bölüm, 'Şimdi'nin Katmanları', 'Kronos ve Tempus', 'Karmaşıklık', 'Karakterlerin Değişken Tutarlılıkları' ve 'Illham Verici (Ödünç Alınmış) Kavramlar' olmak üzere beş alt başlıkta değerlendirilmektedir. Antik mitolojiden örnekler çerçevesinde zamanın hızının ve ölçüsünün değişkenliği üzerinde durulmaktadır. Bergson'un fikirleriyle de desteklenen pasajda, "zamanın formları" konusuna dikkat çekilmektedir. Buna göre, evrendeki 'değişim ve süreklilik' temelinde algilanan tek bir zaman değil, tam tersine çok yönlü bir zaman kavramı düşünülmelidir. Yani, saatin ölçtüğü dışsal zamanın yanı sıra, örneğin içsel süreçleri ölçen başka zamanlar da vardır. Tüm bu farklı zamanlar 'eşzamanlı' ilerleyerek evrensel değişimi tanımlamaktadır. Bu durum, insan doğasını doğrudan konu edinen sanatlar için de geçerlidir. Durmadan hareket eden dişsal zamanın yanı sıra, aynen gerçek hayatta olduğu gibi, temsili karakterlerin içsel zamanı ve de sanat eserinin meydana getirilmesini imleyen yaratıcı zaman anlatının yapısında belirleyicidir. Dolayısıyla, "dünyanın üzerinde izini bırakan" insani yaratıcı süreçte zaman, bu sürecin "içsel” bir parçasıdır.

Bu bağlamda, gerçek hayattaki zamansal boyuta tekabül eden 'istikrarsız' süreçlerin yol açtığı içsel sıkıntılar, ani değişim ve gerilimlere yol açan birikimleri ortaya çıkarmaktadır. Birdenbire ortaya çıkan 'ivme ve patlama' durumları, içsel zamanı manipüle eden dışsal zamandaki birikmişliklerin toplamıdır. Bu düşünce, 'Şimdi'nin Katmanları' alt başlığı içinde Gus Van Sant'ın yönettiği Elephant (2003) filmi bağlamında ele alınmıştır. Metinde, filmin Columbine Lisesi'nde işlenen korkunç cinayetlerin öncesindeki aşırı sıradan görüntüleri uzun 
uzadıya vermesine dikkat çekilmektedir. Durağan, olaysız, günlük olaylar belgeselvari bir kamera rejimiyle sabırla aktarılmıştır. Ancak tercih edilen ve ritim ve tempoyu belirleyen bu sinema dili, Biro'ya göre seyircideki gerilimi an be an yükselmektedir. Akışın bu şekilde türbülansa (katliama) evrildiği anlatı, klasik neden-sonuç ikiliğinin dışında bir etki yaratmaktadır. Düz ve belirli bir zaman dizimi yerine, net olmayan ve kaotik bir zamansallık tercih edilmiştir. Biro'nun ifadesiyle, Gus Van Sant, "anlatı boyunca çizgisel diziye karşıt olarak eşzamanlılığı vurgulayan" bir tercih yapmıştır. Bu bağlamda, anlatının nedensel bağlantılarını oluşturan süreklilik ve değişim, açık değil, tam tersine, fark edilmemiş birikimler ve bunların sonuçları üzerine kurulmuştur.

'Kronos ve Tempus' isimli ikinci alt başlık, makro (gerçek) dünya ve mikro (insani/içsel) dünya arasındaki eşzamanlı olduğu kadar örtüşmez ilişkiye odaklanmaktadır. Kronos ile simgelenen gerçek dünyadaki zaman, insanın dişında ve müdahale edilemez biçimde akar. İnsan, dünyanın kendi kuralları çerçevesinde ve onun içinde yaşar. Tempus ile sembolize edilen insani zaman ise, karmaşık, öngörülemez ve düzensiz şekilde gerçek dünyanın zamanına eklemlenir. Yani, insan aynı zamanda kendi öznel tecrübeleri ve algılamaları çerçevesinde kendi zaman boyutuna sahiptir. Öyküsel temsil de aynı şekilde, bir yönüyle gerçek dünyanın zamanına bağlıdır. Film örneğinde, belirli bir süre boyunca belirli olaylar birbirine eklemlenerek ilerler. Bu anlamda, gerçek zaman gibi çizgisel niteliktedir. Öte yandan, karakterlerin temsili de olsa anlatıdaki varlıkları, insani zamanı da işin içine sokar. Dolayısıyla, filmin akışında beklenmedik bir 'türbülansa' daima yer açılmalıdır. Ancak bu şekilde, yani eylemlerin altındaki içsel güdülerin yanı sıra, bilince etki eden geçmiş ve gelecek arasındaki öznel zamanın yarattığ 1 devinimlerin kaotik karakteri ortaya konulursa 'zengin' bir sanatsal anlatıma varılabilir. Gerçek yaşamda olduğu gibi, sanatsal temsilde de zengin akışı sağlayacak şey, beklenmedik türbülanslara yol açacak olan 'karmaşıklık, düzensiz davranışlar, tesadüfi kargaşa ve atlamalar" temelinde kurulacak anlatı yapısıdır.

Bu nokta, metinde 'Karakterlerin Değişen Tutarlılıkları' alt başlığı içinde Fassbinder' in Maria Braun'un Evliliği (1979) filmi üzerinden örneklenmiştir. Buna göre anlatıdaki ana karakter Maria Braun' un eylemleri birden çok ve karmaşık güdülere bağlıdır. Başlangıçta tüm edimleri 'normal' görünmesine rağmen, ilerleyen bölümlerde 'ani ve ölümcül' olarak nitelenen dönüşler mevcuttur. Dolayısıyla, bu karakterin öyküsel çizgisinde karmaşık güdülerin yol açtığı türbülanslarla şekillenen bir akış vardır. Bu bağlamda, mikro dünyasındaki algılamalarına eşlik eden öznel zamanı onun eylemlerini kuran başlıca öğedir. Biro'nun ifadesiyle, "küçük ölçekli değişimler farklı bir aşamaya; vahşi, kademeli olaylara yol açan büyük ölçekli yeniden düzenlemelere" neden olur.

Bir sonraki alt başlık olan 'İlham Verici (Ödünç Alınmış) Kavramlar'da ise, yine türbülansa sebep olan anlatısal öğelerden biri olarak 'garip çekici' kavramı kullanılmıştır. Fizikçilerin türettiği bilimsel bir terim olarak garip çekici, "bir sistemin 'yoldan çıkmasına', öğelerin duraksız ve düzensiz halde davrandığı bir sürecin farklı aşamalarına geçmesine neden olan etkenler" olarak tanımlanmıştır. Anlatı yapısında türbülans teriminin, "dengeden çıkmaya hazır şeylerin değişiminin başlaması" olarak kavramlaştırıldığı düşünüldüğünde, 'garip çekici' kavramının filmsel zaman dizimine de uygulanabileceği açıktır. Çalışmada bu 
terim, Godard'ın Serseri Aşıklar (1960) filmi üzerinden örneklenmektedir. Buna göre, filmin anlatısında Belmondo'nun oynadığı ana karakterin çaldığı arabayla yakalanmamak için bir polisi öldürmesi, 'garip çekici' olarak işlev görmektedir. Böylece bu eylem, öykünün geri kalanındaki değişim ve türbülanslar için karakterin davranışlarını şekillendiren bir garip çekici görevi görmektedir.

İkinci ana başlık olan “Tempoyu Ayarlamak" ise, özellikle 20. yüzyıldaki gelişmelerin neticesinde hızın gerçek dünyada olduğu kadar, film yapımı sürecinde de kutsanan bir değer haline gelmiş olmasına odaklanmaktadır. Buna göre, çağdaş film yapımında hakim unsur olan "temponun açık ivmesi" diğer süreçlere baskın çıkmaktadır. Bu, sinemanın ilk zamanlarındaki "hareketi yakalamak" dürtüsü açısından bir başarı gibi görünse de, Biro'ya göre, "amaçlı ilerlemeyi yok eden bir noktaya" varmıştır. Çünkü hıza içkin olan "zamanın kontrolsüz daralması" durumu sonucunda seyirci, soyutlamalar, cansız aktarma ve alıntılara hapsolur. İşte bu yüzden, hız, yavaş hareketin varlığıyla dengelenmek zorundadır. Biro'ya göre, zamansallığın önemini kavrayabilmek, filmsel anlatıdaki türbülans ve akışa açılmak suretiyle hızlı ve yavaş oluşumlardaki değerlerin farkına aynı anda varabilmekle mümkündür.

Zamanın, özellikle de insansal zamanın basit bir çizgiselliğin ötesinde olduğu bilgisini yineleyerek başlayan 'Zamanda Yaşamak' isimli alt başlık, zamanın içsel açıdan çok boyutluluğuna dikkat çekmektedir. Buna göre, herhangi bir bireyin günlerinin geçişi, salt hareket-hareketsizlik veya akış-kesinti dikotomileriyle açılanamamaktadır. Bunların yanında, daimi biçimde süregelen olumsallıklar ve sapmaların yarattığı gerilimler, dönüşlerin ve türbülansların değişen akışlarını da işin içine katmak gerekmektedir. Gerçek yaşamdaki bu çok katmanlılık hali, sanatsal (filmsel) temsil için de geçerlidir. Alımlama açısından, izleyicinin alımlama zamanı ile kurmaca anlatının gelişiminin zamanı birbirinden farklıdır. Dolayısıyla, filmsel görüntü dizimi, olay parçalarının birbirinden farklı görüntülere dağılmasıyla bağımsız bir sistem ortaya çıkarır. Anlatının ritim ve temposu aracılığıyla daralan ve genişleyen zaman, alımlamada farklı yoğunlukta duygusal etkilere yol açmaktadır.

Takip eden 'Hücum Eden Hız' alt başlığında da belirtildiği üzere, sinemanın erken dönemlerindeki yönetmenler, hızlı tempolu aksiyon sahnelerinde müthiş bir tatmin bulurken, aynı zamanda eserlerinde yüksek oranda sıkışıklık hissi de yaratmıştır. Günümüzde ise, sinemanın ulaştığı teknolojik boyut tüm hızlı araçları geride bırakmıştır. Bununa birlikte, daha önce de belirtildiği gibi, bu yüksek hız, sıkça konulmuş vurgularla bölünerek etkili olabilmektedir. Bu noktada, çalışmada Scorsese'nin Kızgın Boğa (1980) filminden örnek verilir. Buna göre, filmde tercih edilen hızlı kurgunun arasına serpiştirilmiş duraklama anları, aynı zamanda ana karakterin yükseliş ve düşüş ile karakterize olan öyküsünü yansıtmaktadır. Filmde yapı, "yavaş ve hızlının değerlerini yan yana getirir, siyah ve beyazın karşıtlığına benzer olarak" temsil edilir. Dolayısıyla, 'Akış' alt başlığında vurgulandığı üzere, akış olmadan türbülansın da olmayacağı filmsel dizimde "hareket ve ivme, yalnızca birikim ve ani dönüşüm aracılığıyla" ortaya çıkmaktadır. Bu nokta, Hitchcock'un Sapık (1960) ve Kuşlar (1963) filmleriyle örneklenirken, bu filmlerdeki bütün etki, ritmik bir zirve noktası ve neticesindeki karşıtlık yoluyla üretilmektedir. 
Üçüncü ana başlık olan “Karışık (Genişletilmiş) Öykü Yapıları”, anlatıdaki çoklu olay örgülerini, dolayısıyla da çoklu zamansal boyutlarını irdelemektedir. 'Paralellikler', 'Birleşme Noktaları', 'Mozaikler', 'Epik Anlatı' ve 'Orkestrasyon' alt başlıklarına sahip bölüm, beklenebileceği gibi Altman'ın 'çok anlatılı' filmsel yapılarından örnekler vererek başlamaktadır. Altman filmlerinde ritim, çok katmanlı olay örgüsünün sağladığı karmaşıklık aracılığıyla yaratılmaktadır. 'Mozaik' alt başlı̆̆ında ise, Loach'ın Kerkenez (1969) filmi üzerinden ana karakterin aile hayatı, okulu ve vahşi bir kuşu eğitme süreci parçalı (mozaiksel) bir yapıyla aktarılır. Burada da ritim, karakterin içsel tutkuları ile dışsal baskıların karşıtlığı temelinde akışı oluşturmaktadır.

Ardından gelen 'Epik Anlatı' alt başlığında örneklenen film, Kubrick'in Barry Lyndon (1975) eseridir. Anlatıda gündelik boş ritüellerin, ulaşılmış mekanik eylemlerin ağır bir tempo ile sergilendiğine dikkat çekilmektedir. Dolayısıyla, filmde izleyicinin ilgisini açık tutan sorunun 'ne' değil, 'nasıl' olduğu vurgulanmaktadır. Buna göre Kubrick, anlatıda zaman ve ritmi kasıtlı şekilde uzatarak seyirciyi adeta 'askıda bırakmaktadır'. 'Orkestrasyon' alt başlığında örneklenen Fassbinder' in Berlin Alexanderplatz (1980) yapıtında ise, kentsel yaşamın çok sesli ve imgeli yapısının meydana getirdiği bütünün yarattığı akış incelenmektedir. 'Kolaj' terimiyle tanımlanan filmsel bütün, birbirinden ayrık parçaların, seslerin, imgelerin bir yığının içinde birleşmesinden oluşmaktadır.

Biro'nun belirli bir dizim uyarınca neden-sonuç ardışıklığı kadar dizimin dışına çıkan anlatı unsurlarına verdiği öneme uygun şekilde, takip eden bölümün ana başlığ1 "Konudan Sapmak" olarak belirlenmiştir. Buna göre, belirli bir anlatıda gelişimi ancak 'yabancı' madde girişi sağlayabilir. Dolayısıyla, var olan ve ileri doğru gelişen anlatı, başka bir zamansal boyutta yer alan yeni bir nitelik tarafından bozulur. Böylece bir anlatının içkin ritmi, dizimden sapmalar aracılığıyla gerçekleşmektedir. Özellikle Antonioni başta olmak üzere ünlü modernist yönetmenlerin sık sık konu dışına çıktıkları, 'olumsal ve rastlantısal' sapmalar aracılığılla anlatının ritmini oluşturduklarına dikkat çekilmektedir. Yine bir başka 'sapma' biçimi olarak anlatı içinde hayal gücüne ait fantezi parçaları örnek verilmektedir. Bu yöntem, Polanski'nin Tiksinti (1965) ve Kiracı (1976) filmleri üzerinden örneklendirilmektedir. Benzer bir sapma, dolayısıyla başka bir zamansal boyut biçimi olarak, anlatı karakterlerinin anılarının devreye girmesi ise, Resnais' in Hiroşima, Sevgilim (1959) ve Chris Marker' in doğrudan doğruya zamanda yolculuğu konu alan deneysel çalışması La Jetée (1962) filmleri çerçevesinde açımlanmaktadır. Biro'ya göre Marker'in yapıtı, zamanın gerçek giriftliğini göstermekte ve zamansal algının karmaşıklığını vurgulamaktadır. Diğer bir sapma biçimi olarak rüyaların ele alındığı alt başlıkta, rüyaların özellikle anılardan farklılığının altı çizilmektedir. Sinemanın bizatihi doğasıyla rüyalar arasındaki benzerliğe de dikkat çekilirken, bu konu Bergman'ın Yaban Çilekleri (1957) ve Fellini' nin Sekiz Buçuk (1963) adlı eserleri temelinde irdelenmektedir. "Konudan Sapmak" kisminin son bahsi olarak, ileri atlama (flashforward), Coppola'nin The Conversation (1974) örneği ile aktarılmaktadır.

Takip eden bölüm olan "Zamanda Görmek" bölümü, rasyonalite geleneğince üzeri örtülmüş 'zamansal hakikatleri' sanatın, özellikle de sinemanın görünür kılabildiğini konu edinmektedir. 'Şeylerin yüzü' nün fiziksel çekiciliğin ötesinde zamansal kodları filmin içerisine 
yerleştirdiğine dikkat çekilmektedir. Bu konu, öncelikle 'insan yüzü' bağlaminda detaylandırılmaktadır. İlk akla gelen örnek olarak Bergman'ın Persona (1966) filmindeki devasa yüz çekimlerinin sanatsal ve aynı zamanda 'zamansal' karakteri vurgulanmaktadır. Ardından ise, 'Şeylerin Yüzü' bahsinde, filmlerde insanın dışındaki nesnelerin nasıl yaşamsallık (zamansallık) kazandığı üzerinde durulmaktadır. Eisenstein'in Potemkin Zırhlısı'ndaki (1925) bebek arabası, Chaplin'in Büyük Diktatörü'ndeki (1940) dünya küresi, Hitchcock'un Sapık'ındaki (1960) Bates Motel gibi nesnelerin ana karakterlerin eylemlerine güçlü katkılar vererek zamansal boyutta derinlik sağladığı savunulmaktadır. Ayrıca, güçlü manzara görüntülerinin de aynen nesnelerde olduğu gibi aynı işleve sahip olduğuna işaret edilmektedir. Bunlardan başka, özellikle yavaş temponun filmlerdeki 'sessizlik' ile doğal bir bağıntısı olduğu belirtilmektedir. Bunun en muhteşem örneklerinin Tarkovsky, Bergman, Bresson ve Angelopoulos sinemalarında verildiği vurgulanmaktadır.

Bir başka konudan ayrılma aracılığıyla kesme biçimi olarak 'yineleme' gösterilmektedir. Örneğin Ozu'nun filmlerinde görüntü akışında belli öğelerin sık sık araya giren görüntülerine gönderme yapılmaktadır. Böylece, yani her günkü yaşama ait unsurların sürekli vurgulanmasıyla belirli bir yeknesak zamansallık yakalanmaktadır. Kierkegaard'ın düşünceleriyle Ozu'nun filmleri arasında paralellikler kuran bu kısmı izleyen sayfalarda, 'Mekanizmin Komedisi' aktarılmaktadır. Tati'nin Oyun Zamanı (1967) filmi üzerinden komedilerdeki mekanik tepkilerin yineleme biçim olarak kullanılışı irdelenmektedir. Yinelemenin farklılaşmış bir şekli olarak ise, 'Aynı ama Farklı' kısmında, Kurosawa'nın Rashomon (1950) filmiyle, sinemasal anlatının karmaşıklığına dair radikal bir örnek olduğu vurgulanmaktadır. Filmde, belirli bir olayı kendi açılarından anlatan karakterler aracılığıyla evrensel zaman kavramının reddedildiği, parçalanmış gerçekliğin zamanı da büküp genişlettiği, dolayısıyla farklı bir gerçeklik algısının yaratıldığına değinilmektedir. Bunun daha modern bir örneği olarak ise, Tykwer'in Koş Lola Koş (1998) filmindeki aynı şekilde başlayan olaylar dizisinin üç farklı kurguyla edimsel, zamansal ve mekânsal değişikliklere uğraması, dolayısıyla kaçınılmaz biçimde farklı finallere varması aktarılmaktadır.

Çalışmanın bir sonraki "Odiseuslar" adlı bölümünde, uzam-zaman-tarih kavramları çerçevesinde filmsel anlatının ritim ve temposunu düzenleyen önemli öğeler ele alınmaktadır. Sinemanın gerçekçiliğin çok daha ötesine geçebilen imkânları doğrultusunda, 'kozmik boyutlar'da öyküler anlatabildiğine dikkat çekilmektedir. Bu bağlamda, ilk örnek olarak beklenebileceği gibi genel başlık ismiyle müsemma Kubrick'in 2001: Bir Uzay Macerası (1968) filmi seçilmiştir. Alışılageldiği üzere, filmin anlatıdaki siyah monolit üzerinden felsefi sorgulamalara giriştiği üzerinde durulmaktadır. Kubrick'in kozmik bir '1ssız uzam' yaratarak tuhaf ama çarpıcı bir tempo yakaladığı, ayrıca filmin adındaki Odiseus kelimesinin Homeros'tan beri var olan 'büyük yolculuğun ironik, belirsiz sonucu' şablonuna gönderme yaptığına dikkat çekilmektedir. Yine 2001 filmiyle ilgili bilinen biçimde, Nietzsche'nin ebedi dönüş düşüncesi burada da vurgulanmaktadır. Biro'ya göre filmde asıl önemli olan şey ise, Kubrick'in filmde yarattığı zaman algısıdır. Buna göre, filmsel tasarımın tüm öğelerinin 2001'deki kullanılışı, zamanın varlığını özel bir biçimde işlemeye hizmet etmektedir. 
Anlatısal yolculuğun bir başka türü olarak, 'Bölgenin Labirentinde' alt başlığg doğrudan Tarkovksy'nin İzsürücü (1979) filmine gönderme yapacak şekilde seçilmiştir. Filmdeki karakterlerin ağırlıksız jestleri ve dingin kamera rejiminin amacı, 'zamanın kendisini yontmak', Tarkovsky'den alıntılanan cümleyle, 'sonsuzluğu, zamanın akışını durdurarak anlatmak' anlamına gelmektedir. Biro' ya göre, Tarkovsky tüm yapıtlarında zaman deneyimini zamanın sonuna göre ölçmektedir. Ardından gelen alt bölümdeki Angelopoulos ise, 'Tarih Dolambacı' çerçevesinde anlatılarını kurmaktadır. Onun filmlerinin 'görkemli epik şiir' yapısında olduğu ve böylece özgün bir ritim yaratabildiği vurgulanmaktadır. Buna göre Angelopoulos filmleri, "kaderin, yolun kendisinin, zamanın pençesinde zorunlu bir yolculuk" olduğunu anlatmaktadır. Angelopoulus'un anlatılarında yolculuk, geçmiş ve şimdinin yanı sıra, düş gücünü de içine alarak ve bunların da ötesinde daha derin bir manaya sahiptir. Karakterlerin iç dünyaları, yolculuğun kendisiyle özdeş hale gelir. Bu yönden, Angelopoulos filmlerindeki türbülans ve akış, yolculuğa etki eden dışsal koşullara bağlıdır. Fakat söz konusu özdeşlik nedeniyle içsel motivasyonları da doğrudan etkilemektedir. Zamanın 'sonsuz' kullanımında ustalaşmış yaratıcı ise Bela Tarr'a atıf yapılmaktadır. Tarr'ın yaklaşık sekiz saat süren Şeytan Tangosu (1994) filmi irdelenerek, filmdeki sabır isteyen ağır temponun esasen çiftlikteki umutsuzluk kapanına kısılmış karakterlerin iç dünyasını simgelediğine işaret edilmektedir. Oradan gitmek -sadece gitmek- isteyen karakterler, "varoluşun dayanılmaz sürekliliği" içinde hapsolmuş durumdadır. Tarr, zamanın acı dolu geç(emey)işini geniş açılar, yakın çekimler ve aşırı yavaş bir tempo ile aktarmaktadır.

Benzer bir varoluşsal çıkışsızlık, takip eden bölümdeki "Günlük Ritüeller" başlığı altındaki 'Tekdüzeliğin Ritmi' bahsinde analiz edilmiştir. Sürekli takip eden aynılığın yinelemelerle sergilenmesi, zaman ve uzamdaki "yavan varoluş" aktarımı için uygun bir yol olarak belli yönetmenlerce tercih edilmiştir. Örneğin Haneke'nin Yedinci Kıta (1989) filmindeki modern ailenin sıkıcı yaşamı böyle bir tercih içermektedir. Filmin uzun bir bölümündeki kısa çekimlere eşlik eden kararmalarla, filmin temposu bilinçli şekilde anlaşılmaz kılınmaktadır. Hiçbir dikkat çekici şey olmadan ilerleyen anlatı, aslında en sondaki büyük şiddet patlamasına hazırlıktır. Çalışkan kocayı canlandıran ana karakter krize girerek tüm eşyalarını, parasını yok eder. Dolayısıyla Haneke, önce dikkat çekici bir yavaşlıkla oluşturduğu akış temposunu bu şiddetli dönüşle bir türbülansın içine sokmuş olur.

Benzer bir karakter yapılandırılması olarak Jarmusch ve Kaurismaki'nin filmlerinde atalet içinde temsil edilen karakterler gösterilmektedir. Örneğin Jarmusch'un Ölü Adam (1995) filminin western türünün aksiyon yüklü niteliğini tersine çevirdiği ve karakterlerin çatışma anlarında bile uyuşukça hareket etmelerinin benzersiz bir komedi fırsatı yarattığına dikkat çekilmektedir. Yine Kaurismaki' nin yapıtlarında da, “artık beklentilerin olmadı̆̆ı, hiçbir şeyin kendilerini şaşırtmadığı bir tür bitkinlik ve alaycı bezginlik" bulunduğu vurgulanmaktadır. $\mathrm{Bu}$ iki yönetmenin özel stilleri aracılığıyla tempo ve ritimde özgünlük yakaladığı ve kendi filmsel zamanlarını inşa ettiklerini söylemek olanaklıdır.

Anlatının inşa edilmesinde en önemli noktalardan biri olan 'final' öğesi, çalışmanın "Sonlanışlar" ana başlığı altında irdelenmektedir. Biro'ya göre, anlatının finalini hazırlamak, daima etkili bir ritim tasarımı için mühim bir meydan okuma anlamına gelmektedir. Bunun 
için farklı yollar denenmiştir. Yönetmen, türbülansa neden olan yüksek bir zirveyi tercih edebilir veya tam aksine, şairane bir bitim için sakin bir son hazırlayabilir. Sinema tarihindeki biçimsel final tercihlerinden biri, 'açık son'dur. Beklenebileceği gibi, bu türün en ünlü örneği Truffaut'un 400 Darbe (1959) yapıtıdır. Biro'ya göre böylesi bir tercih, “zekice ya da zorlama mutlu sondan kurtulma" manasına gelmektedir. Anlatının nihayetlendirilmesi için bir başka yol ise, geciktirim ya da ertelemedir. Burada, tüm anlatıya hâkim olan şimdiki zamanın genişletilmesi ve böylece hızlı, birden sona eren bir finalden kaçınılmaktadır. Örneğin, Penn'in Bonnie ve Clyde (1967) filminin son sahnesindeki ağır çekim tercihi, belirli bir geciktirim ve ertelemeye hizmet etmektedir. Diğer bir final tercihi ise, 'beklenmedik tecelli' olarak adlandırılmaktadır. Ridley Scott'un Thelma ve Louise (1991) filminde, hızlı kurgunun ve kaçmakovalamaca sinemasının tüm gerekliliklerinin yerine getirildiği, finalde ise iki ana karakterin arabayı uçuruma sürmesiyle, yani beklenmedik bir tecellinin gerçekleşmesiyle ilginç bir bitişe imza atıldığına dikkat çekilmektedir.

Çalışmanın "Zamanın Stratejileri" adlı son ana bölümü, tüm metnin sonuç kısmı mahiyetini taşımaktadır. Biro, metnin tamamında ritim ve temponun karmaşık ilişkisinin yanı sıra, aralarındaki özel etkileşimi de incelemeyi amaçladığını belirtmektedir. Biro'ya göre, ritim, filmsel tasarımın tüm öğelerinin bütünde düzenlenmesini sağlayan temel öğedir. Sadece filmsel süreyi gösteren zamansal bir oluşum değil, aynı zamanda "malzemelerin çeşitli yönleri arasındaki etkileşimin de bir sonucu" olan unsurdur. Diğer taraftan, tempo ise şekillendirici etkiye sahip ritme bağlı olan bir öğedir. Ritim, dramatik tasarımın bizatihi kendisiyken, bunun hızlı mı yoksa yavaş mı olacağı (temposu) ikincil problemdir. Ritim ve tempo arasındaki karmaşık ilişki, film tasarımının bütünündeki öğelerin tümüne bağlı olarak ortaya çıkmaktadır. Biro' ya göre, bir öykü anlatıcısı, zamanda yaşayan ve düşünen biri olduğu kadar, sürekli zamandan bahseden bir "zaman heykeltıraşı" demektir. Yapıtlarında zamanı yorumlar, anlatısı aracılığıyla zamanı "insani” kılar.

Sonuç olarak, Yvette Biro'nun çalışması, 'zaman' gibi anlaşılması meşakkatli bir kavramı filmsel tasarımın temel parçaları olarak gördüğü ritim ve tempo üzerinden tartışmaktadır. Sinema tarihine damga vurmuş birçok yönetmenin filmlerinden verilen örnekler felsefi düşüncelerle de ilintilendirilerek aktarılmaktadır. Bu yönden, filmsel tasarımın bütününü felsefi bir bakış açısından algılamak isteyenler için önem taşıyan bir niteliğe sahiptir. Bununla birlikte, belirli bölümlerde tekrara düşerek metnin akıcılığının zedelendiğini belirtmek gerekmektedir. Yine çok fazla alt başlık seçimiyle, esasen birbirlerini kapsayabilecek konuların farklı bölümlerde ama aynı filmlerle örneklendirilmesi, okurda bir 'aynılık' hissi yaratmaktadır. Fakat genel olarak incelendiğinde çalışmanın, sinema-felsefe alanında düşüncelerini derinleştirmek isteyenleri tatmin edecek düzeyde olduğu yargısına varmak olanaklıdır. 